\title{
MÉTODOS DE ENSINO UTILIZADOS NOS CURSOS DE LICENCIATURA EM CIÊNCIAS BIOLÓGICAS EM FLORIANO, PIAUÍ, BRASIL E SUA INFLUÊNCIA NO PROCESSO DE ENSINO E APRENDIZAGEM
}

\author{
JORLANNIA DA SILVA FIGUEREDO \\ Licencada em Ciências Biológicas pela Universidade Federal do Piauí. \\ E-mail: jorlanniafigueredo@hotmail.com \\ RAQUEL SOUSA VALOIS \\ Mestrado em Educação - Educação Ambiental pela UNESP/Rio Claro, licanciada em Ciências Biológicas \\ pela Universidade Federal do Piauí. Professora do curso de Licenciatura em Ciências Biológias da \\ Universidade Federal do Piauí/CAFS. E-mail: rsvalois@ufpi.edu.br
}

\section{RESUMO}

Este trabalho tem como objetivo analisar o processo de ensino-aprendizagem praticado no âmbito dos dois cursos de Licenciatura em Ciências Biológicas, em duas Instituições Federais de Ensino Superior (IFES), na cidade de Floriano, Piauí, Brasil, a partir da visão de docentes e discentes, a respeito dos métodos de ensino utilizados nas disciplinas, identificando os mais utilizados e o modo como estes facilitaram e/ou dificultaram a aprendizagem. Para isso, buscamos embasamento em referencial teórico que tece discussões e reflexões sobre métodos de ensino e recursos didáticos e importância no processo de ensino-aprendizagem. $\mathrm{O}$ instrumento utilizado para a coleta de dados foram questionários semiestruturados aplicados com 32 discentes e 15 docentes. Os dados foram posteriormente organizados e analisados a partir da análise de conteúdo. Os principais resultados apontaram uma contradição de que, apesar da aula expositiva ser considerada por muitos discentes como um método de ensino eficaz, é também um dos que mais recebe críticas e que menos desperta interesse nos alunos; as aulas práticas, sejam elas de campo ou em laboratório, proporcionam aos discentes uma melhor compreensão do assunto visto nas aulas expositivas, e está entre os métodos mais bem aceitos; alguns professores, por sua vez, consideram que a discussão de artigos e/ou debates são métodos que despertam interesse nos alunos e estes estão diversificando suas aulas através do uso de aulas práticas, vídeos e grupos de discussão. Podemos inferir que na formação inicial tanto os docentes quanto os métodos de ensino utilizados por estes podem influenciar na formulação de um exemplo do ser docente em algum momento do exercício profissional dos licenciados.

Palavras- chave: Procedimentos de ensino. Ensino Superior. Licenciatura em Ciências Biológicas. Professores. Alunos

\section{TEACHING METHODS USED IN THE DEGREE COURSES IN BIOLOGICAL SCIENCES IN FLORIANO, PIAUÍ, BRAZIL AND THEIR INFLUENCE ON THE TEACHING AND LEARNING PROCESS}

\begin{abstract}
This work aims to analyze the teaching-learning process practiced in the scope of the two undergraduate courses of Biology Sciences of two Federal Institutions of Higher Education (IFES), in the city of Floriano, Piauí, Brazil, from the teachers and students perspectives regarding the methods used in disciplines, identifying the most used and how these facilitated and/or hindered the learning process. In order to do this, we seek to base a theoretical framework that weaves discussions and reflections about teaching methods and didactic resources and their importance in the teaching-learning process. The instrument used for the data collection was semi-structured questionnaires applied with 32 students and 15 teachers. The data were later organized and analyzed by means of the content analysis. The main results pointed out a contradiction in that, although the lecture is considered by many students as an effective teaching method, it is also one of the most criticized and less exciting method to students; The practical classes, whether in the field or in the laboratory, give the students a better understanding of the subject seen in the lectures, and is among the most accepted
\end{abstract}


methods; Some teachers, in turn, consider that discussion of articles and / or debates are methods that arouse interest in students and they are diversifying their classes through the use of practical classes, videos and discussion groups. We can infer that in the initial training both the teachers and the teaching methods used by them can influence the formulation of an example of the teacher being at some point in the professional practice of the graduates.

Keywords: Teaching Procedures. Higher education. Degree in Biological Sciences. Teachers. Students

\section{INTRODUÇÃO}

Durante muitos anos, a docência no Ensino Superior (ES) não era considerada objeto de estudos de especialistas. Entretanto, essa situação mudou a partir de 2001, com a publicação das Diretrizes Curriculares Nacionais para os cursos superiores, pelo Ministério da Educação (MEC), como aponta Oda e Delizoicov (2011). Segundo esses autores, diversas pesquisas já foram realizadas, desde de estudos das competências pedagógicas no ensino superior até àquelas que investigaram a constituição da profissionalidade docente.

Pachane e Pereira (2004) afirmam que na proposta inicial do então Senador Darcy Ribeiro, parte da legislação brasileira sobre a educação mencionava a necessidade da formação pedagógica do professor universitário. Entretanto, esse trecho foi excluído da Lei de Diretrizes e Bases da Educação Nacional (LDB), restando apenas o Artigo 66 - “a preparação para o exercício do magistério superior far-se-á em nível de pós- graduação, prioritariamente em programas de mestrado e doutorado”.

Nessa perspectiva, os docentes do ES têm sido historicamente expostos a uma série de desafios, os quais incluem acompanhar a evolução dos acontecimentos, sendo elas científicas e tecnológicas, para manter-se desempenhando sua profissão de tal forma que seu modo de ensinar esteja centrado em uma educação voltada para novos procedimentos de ensino, que seja favorável ao desenvolvimento cognitivo e intelectual dos discentes (LIMA; VASCONCELOS, 2006).

Considerando que a formação inicial é o começo da busca de uma base para o exercício da atividade docente, é necessário estabelecer concepções que leve o docente à reflexão, no sentido de promover os saberes da experiência conjugados com a teoria, permitindo uma análise integrada e sistemática da sua ação educativa, tornando assim necessário apresentar e debater durante a formação inicial, situações que envolvam teorias e práticas, de maneira que possam ser vivenciadas pelo futuro profissional (BARREIRO, 2006). 
Quadros (2006) elucida que se o curso de formação inicial de professores não tiver a capacidade de proporcionar uma formação sólida “[...] certamente estará formando um professor inseguro, que será 'adotado' pelos livros didáticos mais próximos a ele, sem que se tenha autonomia para tomar decisões relacionadas ao conteúdo que irá ensinar" (p. 12, grifo do autor).

Em relação ao curso superior de Ciências Biológicas, Oda e Delizoicov (2011) chamam atenção ao afirmar que "[...] a docência universitária em Biologia, entretanto, é tema que requer investigação, constituindo ao que parece, até o momento, uma lacuna" (p. 103). Uma dessas lacunas, por exemplo, é encontrada nos cursos de licenciatura, que deveria buscar dar aos futuros professores, conteúdos específicos necessários para a atuação do docente ao trabalhar o currículo dos ensinos fundamental e médio, como proposto nos Parâmetros Curriculares Nacionais (PCN's).

Apesar dos constantes avanços da ciência e das tecnologias, observa-se que o Ensino de Biologia (EB) continua sendo, na maioria dos casos, ainda limitado às aulas expositivas com mínima participação do alunado. Mas é válido salientar que cada estudante aprende de uma forma diferente e cabe a cada docente descobrir alternativas de ensino e aprendizagem que possam está contribuindo para o crescimento das competências dos discentes. Diante disso, Veiga (1989, p. 105) já afirmava que:

Cabe ao professor decidir o que ensinar para os seus alunos e isto implica selecionar e organizar conteúdos, segundo critérios e princípios específicos para esse fim. A tarefa de previsão e viabilização do conteúdo consiste em saber quais conteúdos devem ser transmitidos, em considerar que experiências dos educandos devem ser incorporadas aos novos conteúdos, em priorizar aspectos essenciais, o que permitiria um avanço qualitativo. Convém ressaltar ainda que os conteúdos a serem transmitidos, por não se constituírem em assuntos isolados e independentes, requerem por parte do professor um trabalho de organização e sistematização.

Pozo (2000) adverte que os métodos $^{1}$ de ensino utilizados em sala de aula interferem fortemente no processo de ensino e aprendizagem dos discentes, sendo que seu uso deverá ser de acordo com o conteúdo a ser ministrado, dos objetivos que se deseja atingir e da aprendizagem a ser desenvolvida.

Ausubel (1980, citado por OLIVEIRA, 2005) destacava em seus estudos que aquele professor que se permite fazer o uso de técnicas expositivas combinadas a outros

\footnotetext{
${ }^{1}$ Entende-se por método como “o caminho para atingir um objetivo” (LIBÂNEO, 1994, p.150).
} 
tipos de práticas pedagógicas, tais como estudos dirigidos ${ }^{2}$, dramatização ${ }^{3}$, estudo de caso $^{4}$ dentre outros, poderiam favorecer um melhor aproveitamento na aquisição dos conceitos, durante o processo de ensino em sala de aula.

Reforçando essa posição, Krasilchik (2009) salienta ser imprescindível o uso de diferentes métodos de ensino, sendo estes norteadores para aquisição de competências, logo que os discentes possuem estilos de aprendizagem distinta.

Na mesma linha de raciocínio, Berlesi (2011) aponta que a utilização de outros métodos de ensino, a saber: práticas em laboratório e na sala de aula, aulas de campo, jogos (lúdicos), debates, entre outras, quando ocorrem, se dá por iniciativas de alguns docentes, levadas a adiante com grande esforço pessoal desses profissionais que encontram tempo e disposição para elaborar aulas diferenciadas.

Soncini e Castilho Júnior (1988), já afirmavam que diversos conteúdos podem ser trabalhados com diferentes métodos, com um mesmo método, ou ainda com uma combinação deles. Porém, torna-se desejável, que se assegure uma dinâmica de aula capaz de estimular o interesse dos alunos, de instigá-los a resolver os problemas que devem ser manifestados da própria atividade, organizada e orientada pelo professor para a construção de um conceito. Por isso, é necessário variar os métodos e as atividades de acordo com os conteúdos e as capacidades que se pretenda desenvolver.

Diante disso, os diferentes procedimentos de ensino auxiliam no processo de ensino-aprendizagem, pois os alunos interagem com as dinâmicas aplicadas em sala de aula seguidas da abordagem do conteúdo. Neste contexto é importante estudos que visam conhecer os métodos utilizados pelos professores de ES, bem como porque tais métodos são mais utilizados e assim tentar inferir quais as (des) motivações dos alunos com as diversas disciplinas do curso de Ciências Biológicas, e identificar, segundo a opinião dos alunos, quais os métodos que mais favorecem a construção do conhecimento.

\footnotetext{
2 “É um procedimento de ensino por meio do qual o aluno executa um trabalho proposto e orientado pelo professor, de preferência, em sala de aula" (CARLINI, 2004, p.59).

3 "É um procedimento de ensino que objetiva a representação de uma situação do cotidiano, fato ou fenômeno social, pelos alunos" (CARLINI, 2004, p.45).

4 "É um procedimento de ensino que se apoia na apresentação aos alunos de uma situação real ou simulada, relativa ao tema em estudo, para a análise e encaminhamento de solução" (CARLINI, 2004, p.56).
} 
Tendo em vista a importância dos diferentes procedimentos de ensino que visam à construção do conhecimento do alunado, diversos trabalhos já tiveram a mesma temática da presente pesquisa, dentre eles apontamos: Marasini (2010), que buscou analisar o que os professores consideram como recursos didático-pedagógicos, como também quais as áreas da Biologia consideravam ser importante sua utilização; Rosa (2012) que almejava saber se os professores realizavam aulas diferenciadas, como também ter o conhecimento de sua frequência; e por fim, Passau (2010) que procurou analisar os fatores que influenciam a utilização de filmes como recursos didáticos pelos docentes.

Diante da problemática apresentada acima, cabe-nos os seguintes questionamento: Quais são os métodos de ensino mais utilizados em dois cursos de Licenciatura em Ciências Biológicas e por que docentes fazem essas escolhas? Segundo a opinião de discentes desses cursos, como os métodos de ensino influenciam em sua aprendizagem?

O presente trabalho objetiva analisar o processo de ensino-aprendizagem praticado no âmbito dos cursos de graduação dos Institutos Federais de Ensino Superior de Licenciatura em Ciências Biológicas, na cidade de Floriano - Piauí, a partir da visão dos docentes a respeito dos métodos utilizados em suas disciplinas, bem como a visão dos alunos sobre seus processos de aprendizagem, perante os métodos de ensino utilizados durante a graduação, identificando os mais utilizados e o modo como estes facilitaram e/ou dificultaram sua própria aprendizagem.

\section{DELINEAMENTO DA PESQUISA}

\section{Local de pesquisa}

A presente pesquisa se insere no campo da investigação qualitativa, na área da educação. De acordo com Gatti (2002, p. 12-13), pesquisas no âmbito da educação tendem a trabalhar algo direcionado a seres humanos ou com eles próprios e visam compreender "[...] uma vasta diversidade de questões, de diferentes conotações, embora todas relacionadas complexamente ao desenvolvimento das pessoas e das sociedades.”.

A expressão investigação qualitativa é utilizada “[...] como um termo genérico que agrupa diversas estratégias de investigação que partilham determinadas características" (BOGDAN E BIKLEN, 1994, p.16), tais como: (1) possuir o ambiente 
natural como fonte direta de dados, tendo o pesquisador como principal instrumento de coleta de dados; (2) os dados possuem caráter essencialmente descritivo; (3) foco maior no processo do que no produto, ou seja, o pesquisador se interessa mais pelo processo em si do que propriamente pelos resultados; (4) o foco das atenções do pesquisador é dado, acima de tudo, no significado que os participantes atribuem às suas experiências; e (5) a análise de dados tende a ser feita de forma indutiva (BOGDAN E BIKLEN, 1994, p.48).

A presente pesquisa ocorreu em duas Instituições Federais de Ensino Superior ${ }^{5}$ (IFES), ambas da cidade de Floriano-Piauí: Campus " $\mathrm{X}$ " fundado no mês de março do ano de 2009 e Campus "Y", criado em dezembro de 2002, apesar de já existir com denominação diferente.

O Campus "X" possui quatro cursos de ensino superior: Administração e Enfermagem, ambos bacharelados, e Pedagogia e Ciências Biológicas, ambos licenciatura. Desde o ano de sua fundação formaram-se apenas uma turma de bacharéis em Administração e outra de licenciados em Pedagogia e Ciências Biológicas.

O curso de Ciências Biológicas do Campus " $X$ " conta com 22 docentes que ministram aulas em todos os módulos de acordo com sua área de atuação, e desse total apenas 12 são lotados no curso. Optamos por aplicar os questionários com os professores com formação inicial em Ciências Biológicas, o que totalizou 12 docentes, dos quais 10 participaram da pesquisa.

O Campus "Y" possui cursos técnicos na modalidade Integrado, Subsequente/Concomitante e Programa Nacional de Integração da Educação Profissional com a Educação Básica na Modalidade de Educação de Jovens e Adultos (PROEJA) nas áreas de Construção Civil (curso de Edificações), Indústria (curso de Eletromecânica) e Informática (curso de Informática), bem como os cursos superiores de Tecnologia em Análise e Desenvolvimento de Sistemas (TADS) e Licenciaturas em Matemática e Ciências Biológicas.

O curso de Licenciatura em Ciências Biológicas do Campus "Y" possui 13 docentes que ministram aulas em todos os módulos de acordo com sua área de atuação, e desse total apenas 6 docentes são lotados no curso, dos quais 5 possuem formação

\footnotetext{
${ }^{5}$ Por questões de ética e a fim de garantir o anonimato das IFES, bem como dos sujeitos de pesquisa, nesse presente estudo tais instituições serão tratadas como " $\mathrm{X}$ " e "Y".
} 
inicial em Ciências Biológicas. Desde o ano de sua fundação, já se formaram 6 turmas de licenciados em Ciências Biológicas.

O Campus "X" e o "Y" foram escolhidos por se tratarem de IFES da cidade de Floriano e também por não haver indícios até o momento desse estudo, publicações de trabalhos a respeito de métodos de ensino envolvendo os cursos de Licenciatura em Ciências Biológicas de Instituições Federais de Ensino Superior no município.

\section{Coleta de dados}

$\mathrm{O}$ instrumento utilizado para a coleta de dados foram questionários semiestruturados, com questões abertas, fechadas e de múltipla escolha, aplicados com alunos e professores das IFES. Optamos por esse tipo de questionário, pois promove maior possibilidade de discussão dos dados também de questões subjetivas.

De acordo com Gil (1999, p.128) o questionário pode ser definido como "a técnica de investigação que é composta por um número mais ou menos elevado de questões apresentadas por escrito às pessoas, tendo por objetivo o conhecimento de opiniões, crenças, sentimentos, interesses, expectativas, situações vivenciadas etc.”.

Os participantes ${ }^{6}$ desse estudo foram os discentes e docentes de ambas as instituições. Silva (2010) salienta que o participante "é entendido como um indivíduo que elabora conhecimentos sobre a realidade que o circunda e, desse modo, pode contribuir para significar os dados de pesquisa e interpretá-los" (p. 79).

A coleta de dados ocorreu no período de 23 de dezembro de 2013 a 15 de janeiro de 2014. Os questionários semiestruturados foram aplicados com os discentes do período noturno do Campus "Y", e com os discentes de período integral do Campus "X", ambos os graduandos pertencentes ao VIII módulo, ou seja, os alunos formandos em Licenciatura em Ciências Biológicas. Os docentes de ambas as IFES também foram sujeitos de pesquisa, seguindo o critério de possuírem formação inicial em Ciências Biológicas.

Deste modo, os questionários foram aplicados com 10 docentes e com 22 discentes, do Campus "X" e com 5 docentes e 10 discentes pertencentes ao Campus "Y".

\footnotetext{
${ }^{6}$ Cumpre destacar que todos os participantes que responderam ao questionário assinaram o Termo de Consentimento Livre e Esclarecido (TCLE) concordando em participar, voluntariamente, desta pesquisa.
} 


\section{Análise dos dados}

Após a coleta de dados junto às instituições, utilizamos como método para a organização e interpretação dos dados obtidos por meio dos questionários, a técnica de “análise de conteúdo", proposto por Lawrence Bardin, pois como o foco desta pesquisa é investigar e analisar quais os métodos de ensino utilizados em cursos de graduação em Ciências Biológicas, bem como quais as considerações que tanto docentes quanto discentes fazem a respeito de tais métodos, acreditamos que a análise de conteúdo nos permite qualificar as vivências e percepções dos sujeitos sobre determinado objeto e seus fenômenos. (BARDIN, 2009), sendo assim, um método que atende ao objetivo deste presente estudo.

De acordo a autora supracitada, o método "análise de conteúdo" pode ser definido como:

Um conjunto de técnicas de análise das comunicações visando obter por procedimentos sistemáticos e objectivos de descrição do conteúdo das mensagens indicadores (quantitativos ou não) que permitam a inferência de conhecimentos relativos às condições de produção/recepção (variáveis inferidas) destas mensagens (p. 44).

Ainda de acordo com a autora, a análise de conteúdo é constituída por três etapas que se articulam em um movimento dinâmico. A primeira é a pré-análise, etapa que consiste na organização do material e momento em que ocorre a "leitura flutuante"primeiro contato com os documentos a serem analisados, o que permite ao pesquisador apropriar-se do texto e envolver-se por impressões e formular hipóteses, além de encontrar elementos de maior frequência. O corpus documental deste estudo foi constituído dos questionários semiestruturados aplicados aos sujeitos de pesquisa, que foram transcritos em arquivos de word para pré-análise.

A segunda etapa é a exploração dos dados, na qual o material é submetido a um estudo mais aprofundado, envolvendo a codificação dos dados brutos dos textos, transformando-os em recortes, enumerando-os e posteriormente construindo categorias. No caso desta pesquisa, estas foram criadas a posteori, ou seja, emergiram a partir da análise dos dados.

A terceira e última etapa, tratamento e a interpretação dos resultados obtidos, é o momento em que ocorrem as inferências, a partir da interpretação da relação entre os dados obtidos e a fundamentação teórica. A interpretação dos dados obtidos neste estudo se deu a partir da discussão à luz de referencial teórico que tece discussões e 
reflexões sobre métodos de ensino e recursos didáticos utilizados por docentes em educação básica, bem em cursos de formação inicial de professores e sua importância no processo de ensino-aprendizagem (POZO, 2000; LORENZETTI; DELIZOICOV, 2001; KRASILCHIK, 2009; MARASINI, 2010; BERLESI, 2011; ROSA, 2012; SASSERON, 2013)

\section{RESULTADOS E DISCUSSÃO}

\section{Perfis dos participantes: discentes}

Ao analisarmos os dados pessoais dos 32 discentes do último módulo do curso de Licenciatura em Ciências Biológicas de ambas IFES, observamos que do seu total, $78,12 \%$, ou seja 25 discentes, pertenciam ao sexo feminino e $21,87 \%$ ao sexo masculino (TAB. 1).

Tabela 1 - Dados pessoais dos discentes das instituições que participaram do questionário.

\begin{tabular}{c|c|c|c|c|c}
\hline \multicolumn{2}{c|}{$\begin{array}{c}\text { Questão 1 (Dados } \\
\text { pessoais) }\end{array}$} & Campus X & Campus Y & \multicolumn{2}{c}{ Total $(\boldsymbol{X} \boldsymbol{e}$ Y) } \\
\hline \multirow{3}{*}{ Sexo } & & Quantidade & Quantidade & Quantidade & $\%$ \\
& $\mathbf{M}$ & 3 & 4 & 7 & $21,87 \%$ \\
\cline { 2 - 6 } & $\mathbf{F}$ & 19 & 6 & 25 & $78,12 \%$ \\
\hline \multirow{3}{*}{$\begin{array}{c}\text { Faixa } \\
\text { etária }\end{array}$} & $\mathbf{1 8 - 2 0}$ & 2 & 1 & 3 & $9,37 \%$ \\
\cline { 2 - 6 } & $\mathbf{2 1 - 2 3}$ & 14 & 4 & 18 & $56,25 \%$ \\
\cline { 2 - 6 } & $\mathbf{2 4 - 2 6}$ & 2 & 4 & 6 & $18,75 \%$ \\
\hline
\end{tabular}

Fonte: Dados da própria autora. (2014)

Esses resultados vão ao encontro com os dados de Brito (2007) que verificou o perfil dos alunos que optam pelas Licenciaturas de acordo com as informações obtidas do ENADE (Exame Nacional de Desempenho dos Estudantes) do ano de 2005, que em relação ao gênero, constatou-se que $73,7 \%$ pertenciam ao gênero feminino e $26,3 \%$ ao gênero masculino, confirmando a predominância das mulheres nas licenciaturas.

Em relação à faixa etária dos/das discentes das duas IFES (Tabela 1), podemos observar que mais da metade (56,25\%) possui idades entre 21 e 23 anos, o que nos leva a inferir que os/as estudantes estão ingressando na graduação mais cedo e, consequentemente, mais jovens tendem a terminar a graduação, para posterior entrada na disputa no mercado de trabalho.

\section{Docentes}


Ao analisar os dados pessoais dos professores biólogos de ambas as instituições, 8 do total são do gênero masculino e 7 do feminino (Tabela 2).

Tabela 2 - Dados pessoais dos docentes das instituições que participaram do questionário.

\begin{tabular}{c|c|c|c|c|c}
\hline \multicolumn{2}{c}{ Questão 1 (Dados pessoais) } & \multicolumn{2}{c|}{ Campus X } & \multicolumn{2}{c}{ Campus Y } \\
\hline \multirow{3}{*}{ Sexo } & $\mathbf{M}$ & Quantidade & $\mathbf{\%}$ & Quantidade & $\mathbf{\%}$ \\
\cline { 2 - 5 } & $\mathbf{F}$ & 5 & $50 \%$ & 3 & $60 \%$ \\
\cline { 2 - 5 } & $\mathbf{2 0 - 3 0}$ & 4 & $50 \%$ & 2 & $40 \%$ \\
\hline \multirow{3}{*}{$\begin{array}{c}\text { Faixa } \\
\text { etária }\end{array}$} & $\mathbf{3 1 - 4 0}$ & 4 & $40 \%$ & 1 & $20 \%$ \\
\cline { 2 - 6 } & $\mathbf{4 1 - 5 0}$ & 2 & $20 \%$ & 2 & $40 \%$ \\
\cline { 2 - 6 } & Acima de 50 & - & $0 \%$ & 1 & $20 \%$ \\
\hline
\end{tabular}

Fonte: Dados da própria autora. (2014)

A partir dos dados acima, podemos notar que não há diferença representativa entre a quantidade de docentes do sexo masculino e feminino em ambas as instituições. Já em relação à faixa etária, observamos que 11 dos 15 docentes possuem idades entre 20 e 40 anos.

Dados do Resumo Técnico do "Censo da Educação Superior 2013” produzido pelo Instituto Nacional de Estudos e Pesquisas Educacionais Anísio Teixeira (INEP), mostram que nas Instituições de Ensino Superior (IES) públicas há predomínio de docentes do sexo masculino, com idade mais frequentemente observada sendo a de 36 anos. Notamos que em relação ao gênero, os dados da nossa pesquisa não coincidem com os do Censo, mas podemos notar que a idade dos docentes da pesquisa do INEP está abarcada dentro de uma das faixas-etárias (31-40 anos) mais frequente dos nossos sujeitos de pesquisa.

Já a faixa-etária de 21-30 anos, coincide com os dados acima, Pires (2007) ao traçar o perfil do professor do curso de graduação de Biologia na Universidade Estadual de Goiás, constatou que a faixa etária dos professores que concluem seus cursos diminui a cada vez, “[...] uma vez que em outros tempos tanto o mestrado quanto o doutorado, eram pretensões de pessoas com idade mais avançada" (p.35).

Quanto à experiência profissional e formação dos docentes, foram destacados três eixos: exercício docente, titulação e o tipo de vínculo dentro da instituição de ensino (Tabela 3).

Tabela 3 - Experiência profissional dos docentes das instituições que participaram questionário.

\begin{tabular}{l|c|c|c|c|c}
\hline Questão 1 (Experiência profissional) & \multicolumn{2}{|c|}{ Campus X } & \multicolumn{2}{c}{ Campus Y } \\
\hline & & Quantidade & $\%$ & Quantidade & $\%$ \\
\hline
\end{tabular}




\begin{tabular}{|c|c|c|c|c|c|}
\hline \multirow{4}{*}{$\begin{array}{l}\text { Exercício } \\
\text { docente }\end{array}$} & $0-5$ & 4 & $40 \%$ & 2 & $40 \%$ \\
\hline & 6-10 & 3 & $30 \%$ & 1 & $20 \%$ \\
\hline & 11-20 & 1 & $10 \%$ & 1 & $20 \%$ \\
\hline & 21-30 & 2 & $20 \%$ & 1 & $20 \%$ \\
\hline \multirow{3}{*}{ Pós-Graduação } & Especialização & 1 & $10 \%$ & 3 & $60 \%$ \\
\hline & Mestrado & 3 & $30 \%$ & 2 & $40 \%$ \\
\hline & Doutorado & 6 & $60 \%$ & - & $0 \%$ \\
\hline \multirow{2}{*}{$\begin{array}{c}\text { Vínculo } \\
\text { Institucional }\end{array}$} & Efetivo & 8 & $80 \%$ & 4 & $80 \%$ \\
\hline & Substituto & 2 & $20 \%$ & 1 & $20 \%$ \\
\hline
\end{tabular}

Fonte: Dados da própria autora. (2014)

Analisando o exercício docente, constatou-se que $40 \%$ dos 15 docentes que participaram da pesquisa possuem experiência profissional entre 0 a 5 anos, em ambas as instituições, sendo que no Campus X, há $30 \%$ de docentes com experiência profissional de 6 a 10 anos. Tanto no Campus X quanto no Y, a maioria dos docentes possuem vínculo como professores efetivos nas instituições.

Em relação à titulação, a maioria dos docentes do Campus " $X$ ” possui a titulação de doutor, seguida por mestres e especialistas; enquanto que o Campus "Y" conta em sua maioria com especialistas, seguidos de mestres. As áreas de pós-graduação dos docentes são bastante diversas: Meio Ambiente (2); Biologia (1); Genética e Toxicologia Aplicada (1) no Campus "Y" e Entomologia (1); Ciências Biológicas/ Bioquímica (1); Ciências (1); Biotecnologia (1); Saúde e Ambiente (1); Botânica (1); Ecologia/Zoologia (1); Biologia/Zoologia (1); Geociências/Paleontologia (2) no Campus "X".

Os resultados acima a respeito da titulação coincidem com os fornecidos pelo INEP no Censo da Educação Superior, de 2013, quando apontam que nas IES públicas, os docentes possuem mais frequentemente a titulação de doutor e trabalham em regime integral com dedicação exclusiva.

\section{Análises dos questionários}

\section{Discentes}

Os 32 alunos que participaram da pesquisa são chamados respectivamente de

$\mathrm{A}_{22} \mathrm{X}$ e de $\mathrm{A}_{1} \mathrm{Y}$ a $\mathrm{A}_{10} \mathrm{Y}$, mantendo assim suas identidades em sigilo.

Os questionários aplicados aos discentes eram constituídos também por questões subjetivas, que abordavam os métodos utilizados pelo professor dos quais não gostaram, quais 
provocaram maior interesse pela disciplina, se consideravam importante o uso de

métodos

alternativos e quais os métodos de ensino que são interessantes de serem trabalhados, porém pouco utilizados pelo professor. Ao longo deste subitem e em momentos oportunos, será feita a discussão de cada uma dessas questões com base nas categorias que emergiram a partir das respostas dadas pelos alunos.

Com o intuito de evitar repetições e facilitar a discussão, as questões de 2,3 e 4 do questionário serão discutidas em conjunto, já que tratam de uma mesma temática. Solicitamos aos 32 discentes que enumerassem, em ordem crescente, as estratégias que consideravam mais eficazes para a aprendizagem no curso de Ciências Biológicas. Ao analisarmos as respostas, constatamos que entre as mais eficazes, segundo os alunos, estavam as aulas expositivas e as aulas experimentais; e menos eficazes, segundo os discentes, estavam os jogos didáticos. Apenas 3 especificaram em "Outras”, do questionário, como menos eficazes as feiras e as paródias.

Notamos contradição entre as respostas dadas pelos alunos na questão anterior e as dadas na questão sobre os métodos que mais gostavam. Quando questionados sobre os métodos de quais não gostaram, obtivemos respostas variadas, que foram organizadas em categorias apresentadas no Quadro 1. A fim de melhor visualização, foram explicitados excertos ${ }^{7}$ dos discentes das IFES.

Quadro 1 - Métodos utilizados pelo(s) docente(s) que os discentes não gostaram.

\begin{tabular}{|c|c|c|}
\hline CATEGORIA & SUBCATEGORIAS & EXCERTOS \\
\hline \multirow{4}{*}{$\begin{array}{c}\text { Aulas } \\
\text { expositivas/ } \\
\text { Aulas } \\
\text { tradicionais }\end{array}$} & \multirow[b]{2}{*}{$\begin{array}{l}\text { Monótonas/ cansativas } \\
\text { Desinteressantes }\end{array}$} & Campus X \\
\hline & & $\begin{array}{l}\text { "Acho que o uso contínuo desses métodos levam ao } \\
\text { processo de ensino monótono e não interativo". } \\
\qquad\left(\mathbf{A}_{12}\right) \\
\text { "[...] por que as vezes fica cansativo demais sem } \\
\text { falar que não disperta totalmente o interesse do } \\
\left.\text { aluno pela disciplina"( } \mathbf{A}_{18}\right)\end{array}$ \\
\hline & \multirow[b]{2}{*}{$\begin{array}{l}\text { Limitantes do } \\
\text { conhecimento }\end{array}$} & Campus Y \\
\hline & & $\begin{array}{l}\text { "As aulas expositivas eram muito resumidas e de } \\
\text { rápida execução, limitando o conhecimento". }\left(\mathbf{A}_{\mathbf{1 0}}\right)\end{array}$ \\
\hline \multirow[b]{5}{*}{ Seminários } & \multirow{5}{*}{$\begin{array}{l}\text { Conhecimento } \\
\text { fragmentado }\end{array}$} & Campus X \\
\hline & & $\begin{array}{l}\text { "[...] poucos alunos se interessam a fazer, e } \\
\text { estudam apenas uma parte do conteúdo. } \mathrm{O} \\
\text { conteúdo fica fragmentado para o aluno". }\left(\mathbf{A}_{5}\right)\end{array}$ \\
\hline & & Campus $\mathbf{X}$ \\
\hline & & $\begin{array}{c}\text { "Pois faltou o debate de toda a turma sobre o } \\
\text { assunto". }\left(\mathbf{A}_{\mathbf{1 1}}\right)\end{array}$ \\
\hline & & "Porque para melhor aprendizado é necessário a \\
\hline
\end{tabular}

\footnotetext{
${ }^{7}$ Os excertos são ipsis litteris do apresentado pelos sujeitos de pesquisa nos questionários.
} 
Sem debates

\begin{tabular}{l}
\hline Campus $\mathbf{Y}$ \\
\hline “Os seminários foram propostos em grande \\
número, deixando a desejar sobre a respectiva \\
disciplina". $\left(\mathbf{A}_{10}\right)$.
\end{tabular}

\section{Campus $X$}

"Não gostei porque ficou muito difícil de entender o que estava passando." ((A) $)$.

"Para mim a linguagem deveria ter sido em português com legenda em inglês”. ( $\left.\mathbf{A}_{19}\right)$.

\section{Campus $X$}

"porque nem todos participam" $\left(\mathbf{A}_{7}\right)$.

Debates/

Grupo de

discussão

Pouca participação

\section{Campus $\mathbf{Y}$}

"porque muitas vezes nesses grupos de discursão os alunos vão despreparados, e assim não dá de se aprender, e muitos dos alunos não participam, ou

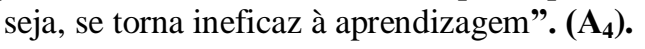

\begin{tabular}{cc}
\hline & Campus $\mathbf{X}$ \\
\cline { 2 - 3 } Aula prática & "[...] classificação de plantas, porque está atividade \\
sem campo & seria melhor em campo". $\left(\mathbf{A}_{\mathbf{1 5}}\right)$. \\
& "[...] certo que foi mais trabalhado em laboratório, \\
mas foi mais com chave de identificação, quando \\
seria mais interessante trabalhar com aulas de \\
campo" $\left(\mathbf{A}_{\mathbf{1 7}}\right)$.
\end{tabular}

Fonte: Dados da própria autora. (2014)

Como foi visualizada no Quadro 1, a aula expositiva, apesar de ser considerada pelos estudantes um dos métodos mais eficazes, é também um dos que mais recebe críticas dos estudantes, quando afirmam que tal método causa monotonia, desinteresse e cansaço.

Krasilchik (1983, p.69) já afirmava que as aulas expositivas eram "melhor do que qualquer outra modalidade didática, [...] serviam, portanto, para introduzir um assunto novo, sintetizar um tópico, ou comunicar experiências pessoais do professor".

Mas, o grande problema que faz gerar desinteresse na aula expositiva nos tempos de hoje, é que ao invés do diálogo, cria-se na maioria das vezes um monólogo, onde só o professor tem a fala; da elaboração do assunto, criamos a simples definição de um conceito, limitando o conteúdo; de organizadores do aprendizado, os professores são tidos como "os donos da verdade", dizendo ao 
aluno o que é certo e errado, sem fazer que o mesmo possa discutir sobre o que é exposto em sala de aula. Diante dessa concepção, Krasilchik (1983) em seus estudos já elucidava essas características como uma desvantagem atinente às aulas expositivas, no qual:

[...] o assunto é polido de tal forma que não dá oportunidade ao estudante de verificar quais as incongruências no raciocínio, as lacunas e as omissões que só serão perspectiveis na hora em que, recorrendo às notas, ele realmente pensa no assunto (p.69).

Reforçando essa posição, Krasilchik (2009) anos mais tarde, salienta ser imprescindível o uso de diferentes métodos de ensino, sendo estes norteadores para aquisição de capacidades, já que os discentes possuem maneiras de aprendizagens distintas. Carlini (2004) indica que "o sucesso da aula expositiva depende quase exclusivamente do professor, tanto para a sua preparação como para o desenvolvimento; [professor] deve despertar a atenção dos alunos, respeitar o ritmo da classe em relação à participação" dentre outras atribuições (p.39 - 40).

Os seminários, também foram apontados como um método de ensino que alguns alunos não gostaram. De acordo com Farias et al. (2008, p.140) o seminário “é um espaço onde as ideias são semeadas, onde temas e problemas são discutidos”.

Carlini (2004) esclarece que "entre as inúmeras formas de trabalho em grupo, o seminário é uma das mais frequentes entre as menções de alunos e professores, em especial, no ensino superior" (p.69). Reforçando a ideia do que foi apresentado, Oda e Delizoicov (2011) elucidam que os seminários compreendem como uma substituição da aula expositiva, ou seja, corresponde uma substituição do trabalho do professor pelo trabalho do aluno, onde o docente escolhe alguns temas do seu conteúdo programático da ementa e repassa para os discentes apresentarem, "comunicando o tema a ser exposto com uma semana de antecedência" (p.113).

Carlini (2004) ainda comenta que embora a principal ação nesse método de ensino seja do discente, encontram-se designadas inúmeras funções para o professor tais como, identificar os conteúdos a ser trabalhado, esclarecer aos alunos a forma de realização do trabalho, e acima de tudo, orientar o trabalho construindo com os discentes um roteiro de pesquisa ajudando-os com os recursos bibliográficos necessários.

Os vídeos estrangeiros também foram apontados entre os discentes de ambas as IFES como um recurso que não foi bem aceito. Provavelmente, essa dificuldade se deve ao fato de alguns alunos não terem domínio de uma língua estrangeira e muitos docentes utilizam vídeos de forma complementar à sua exposição oral, e em muitos casos, eles são exibidos em língua inglesa. É importante que o professor se atente ao nível de conhecimento de outros idiomas de seu alunado, 
caso contrário, algo que deveria ser um auxílio para a contextualização de um conteúdo e que despertasse o interesse, pode se tornar um obstáculo no aprendizado.

Uma possibilidade para amenizar essa dificuldade de aceitação do uso de vídeos em idiomas diferente do português seria a oferta de disciplinas na graduação voltadas para tais línguas e até mesmo que os docentes utilizassem com maior frequência em suas aulas artigos em inglês ou espanhol. Assim, os discentes teriam maior aproximação, conhecimento e afinidade com tais idiomas.

Debates e grupo de discussão foram considerados métodos de ensino que os discentes não gostaram. Entre os motivos apontados estão os de, não haver realmente um debate sobre o tema abordado e o, por acreditarem que não estão preparados para expor seu ponto de vista. Entretanto, acreditamos que, essas formas de ensinar e aprender tornam os alunos mais responsáveis por sua aprendizagem, levando-os a assimilar conceitos e construir conhecimentos de uma maneira mais autônoma, desde que bem orientados para esse fim.

Quando indagados a respeito dos métodos de ensino que haviam the provocado um maior interesse, observamos que as aulas sejam elas práticas, de campo ou em laboratório, proporcionam os discentes uma melhor compreensão do assunto visto nas aulas expositivas, sendo que estas práticas despertam o interesse pelo conteúdo abordado, motivando-os a participarem.

Quadro 2 - Métodos de ensino utilizados em sala de aula que provocou interesse no discente pela disciplina.

\begin{tabular}{|c|c|c|}
\hline CATEGORIA & SUBCATEGORIAS & EXCERTOS \\
\hline \multirow{4}{*}{$\begin{array}{l}\text { Aulas práticas/ } \\
\text { Aulas de } \\
\text { campo/ Aula } \\
\text { de laboratório }\end{array}$} & \multirow{4}{*}{$\begin{array}{l}\text { Construção do } \\
\text { conhecimento }\end{array}$} & Campus X \\
\hline & & $\begin{array}{l}\text { "Por que proporciona ao aluno conhecer as } \\
\text { disciplina de outras forma" }\left(\mathbf{A}_{22}\right)\end{array}$ \\
\hline & & Campus Y \\
\hline & & $\begin{array}{l}\text { "[...] pois embora a teoria seja muito importante, } \\
\text { manuzear, ajuda a construir melhor o } \\
\text { conhecimento sobre certo tema". }\left(\mathrm{A}_{3}\right)\end{array}$ \\
\hline \multirow[b]{2}{*}{$\begin{array}{c}\text { Grupo de } \\
\text { discussão (GD) }\end{array}$} & \multirow[b]{2}{*}{ Estímulo eficaz } & Campus X \\
\hline & & $\begin{array}{c}\text { "favorece um maior apaiado, estimulando o aluno } \\
\text { a estudar." }\left(\mathbf{A}_{\mathbf{6}}\right)\end{array}$ \\
\hline \multirow[b]{2}{*}{ Seminários } & \multirow[b]{2}{*}{ Domínio de conteúdos } & Campus X \\
\hline & & $\begin{array}{l}\text { "Por que trabalha com o emocional, postura, } \\
\text { domínio de conteúdos. Já que sairemos como } \\
\text { professores" }\left(\mathbf{A}_{\mathbf{1 5}}\right)\end{array}$ \\
\hline
\end{tabular}




\begin{tabular}{|c|c|c|}
\hline $\begin{array}{l}\text { Aula teórica } \\
\text { acompanhada } \\
\text { de prática }\end{array}$ & $\begin{array}{l}\text { Compreensão do } \\
\text { conteúdo }\end{array}$ & $\begin{array}{c}\text { "Porque você ver a teoria e logo após fazer a } \\
\text { prática ajuda a entender melhor alguns pontos não } \\
\text { compreendido" }\left(\mathbf{A}_{\mathbf{2}}\right) \\
\text { "Proporciona uma melhor compreensão do } \\
\text { conteúdo dado" }\left(\mathbf{A}_{13}\right)\end{array}$ \\
\hline \multirow{4}{*}{ Debates } & & Campus X \\
\hline & & $\begin{array}{l}\text { "porque exigia um estudo antes ou preparação" } \\
\left(\mathbf{A}_{\mathbf{9}}\right)\end{array}$ \\
\hline & & Campus Y \\
\hline & & $\begin{array}{l}\text { "porque estimulam a construção do senso crítico" } \\
\left(\mathbf{A}_{\mathbf{8}}\right)\end{array}$ \\
\hline
\end{tabular}

Krasilchik (2009) adverte que as aulas prática em campo “[...] são elementos obrigatórios ao curso de Biologia, tendo como objetivos conhecer o ambiente em seus aspectos físicos e ambientais" (p.255), portanto, privá-los dessa modalidade, implicaria no processo de ensino e aprendizagem de qualidade.

Da mesma forma, os métodos como grupo de discussão, debates e seminários, foram levantados por parte de alguns discentes, como procedimentos que não gostaram (Quadro 1) já para outros, estes foram aqueles que mais lhes provocaram interesses (Quadro 2).

Isso se dar por que os discentes possuem maneiras de aprendizagem diferentes, como aponta Krasilchik (2009). Enquanto que uns preferem questionar expressando suas opiniões, outros já se sentem melhor resguardando-as.

Segundo Carlini (2004), o discente, da mesma forma que o docente, é responsável pelo sucesso na execução desses métodos de ensino e, portanto, o discente deve preparar-se para a utilização desses procedimentos realizando leitura da bibliografia indicada; como participar ativa e atentamente do processo de discussão, esclarecendo suas dúvidas, suas divergências, expressando opiniões, posicionamentos, e ouvindo os colegas.

Quando o professor trabalha o conteúdo com aula teórica acompanhada de prática torna a aula significativa, logo que tende acrescentar um sentido novo ao universo de conhecimentos dos alunos, estabelecendo continuamente a relação entre a teoria estudada e a realidade vivida (CARLINI, 2004). Dessa forma, aqueles que não se sentem a vontade com aulas apenas teórica, tende a ter um segundo momento que é a prática para estarem compreendendo o conteúdo exposto 
pelo professor. Portanto, de acordo com Krasilchik (2009), é imprescindível o uso de diferentes métodos de ensino, logo que são eles que irão ajudar na aquisição dos conhecimentos do alunado.

Procedimentos de ensino como debates, aulas de campo e aulas experimentais (Quadro 3) foram avaliados, pela visão dos discentes, como métodos interessantes, porém, pouco utilizados pelos docentes.

Quadro 3 - Métodos de ensino considerados interessantes, porém poucos utilizados.

\begin{tabular}{|c|c|c|}
\hline CATEGORIA & SUBCATEGORIAS & EXCERTOS \\
\hline & & Campus X \\
\hline Debates & Perda de tempo & $\begin{array}{l}\text { "[...] são pouco utilizados porque ainda tem muitos } \\
\text { professores que acham isso uma perda de tempo e } \\
\text { prefere usar o método tradicional" }\left(\mathbf{A}_{\mathbf{1 8}}\right)\end{array}$ \\
\hline \multirow[b]{2}{*}{$\begin{array}{l}\text { Aulas de } \\
\text { campo }\end{array}$} & \multirow[b]{2}{*}{ Falta de tempo } & Campus Y \\
\hline & & $\begin{array}{c}\text { “[...] os professores não tem tempo para nos levar a } \\
\text { campo para pesquisas”. }\left(\mathbf{A}_{2}\right)\end{array}$ \\
\hline \multirow{5}{*}{$\begin{array}{c}\text { Aulas } \\
\text { experimentais }\end{array}$} & \multirow{3}{*}{ Trabalhoso } & Campus X \\
\hline & & $\begin{array}{l}\text { "Pois é um pouco mais trabalhoso e alguns } \\
\text { professores preferem não ter tanto trabalho." }\left(\mathbf{A}_{\mathbf{1 1}}\right) .\end{array}$ \\
\hline & & CampusY \\
\hline & \multirow[t]{2}{*}{ Estrutura Física } & $\begin{array}{l}\text { “[...] pois aqui não temos estrutura laboratorial" } \\
\left(\mathbf{A}_{5}\right) \text {. }\end{array}$ \\
\hline & & $\begin{array}{l}\text { "Por conta de materiais e de capacitação por parte } \\
\text { dos professores.". }\left(\mathbf{A}_{\mathbf{8}}\right) \text {. }\end{array}$ \\
\hline
\end{tabular}

Fonte: Dados da própria autora. (2014)

Os discentes que consideram o debate como um método interessante, porém pouco utilizado pelos docentes, possivelmente são aqueles mais desinibidos e que se sentem mais à vontade para expor suas ideias e seus questionamentos. O importante é que para haver um debate, é preciso que haja participação de toda a turma, incluindo o docente, e este deve estar capacitado para demonstrar domínio sobre o conteúdo, e para que isso ocorra, é necessário tempo disponível para se preparar (KRASILCHIK, 2009).

Em relação às aulas de campo, a autora supracitada, afirma que para exercer essa modalidade não é necessário que ocorra obrigatoriamente, viagens. Levar os discentes para entorno da escola de ensino já pode fazer a diferença e estimular o aluno para a aprendizagem de conteúdos visto em sala, e ainda pouparia o professor de várias preocupações, como por exemplo, uma das mais comuns, o transporte para locomoção. 
De acordo com Marandino, Selles e Ferreira (2009), muitas justificativas são usadas em relação à falta de aulas experimentais - falta de tempo, devido à sobrecarga a ser cumprida pelo professor; estrutura (incluída a falta de materiais) não ser adequada para a execução da modalidade; e a questão do preparo, ou seja, se o docente está habilitado a executar essa modalidade de ensino.

$\mathrm{Na}$ visão dos discentes pesquisados, é de suma importância o professor trabalhar com métodos alternativos ${ }^{8}$ para a obtenção de uma aprendizagem significativa, evitando que os mesmos adquiram apenas uma aprendizagem parcial, ou seja, uma simples memorização dos conteúdos. Pois como já foi exposto até o momento, cada indivíduo tem capacidades cognitivas distintas, o que pode ser visualizados nos excertos abaixo:

"Sim. Pois assim o aluno fica sempre motivado e interessado em participar das aulas, além de deixar a aula com melhor resultado" $\left(\mathrm{A}_{5} \mathrm{Y}\right)$.

"Sim, porque o aluno aprende de várias formas e cada um tem um canal de aprendizagem" $\left(\mathrm{A}_{7} \mathrm{X}\right)$.

\section{Docentes}

Os 15 professores que se dispuseram a participar da pesquisa, são chamados respectivamente de $\mathrm{P}_{1} \mathrm{X}$ a $\mathrm{P}_{10} \mathrm{X}$ e de $\mathrm{P}_{1} \mathrm{Y}$ a $\mathrm{P}_{5} \mathrm{Y}$, mantendo assim suas identidades em sigilo.

Perguntamos aos docentes quais os métodos de ensino que utilizam em sua (s) disciplina (s), e constatamos a partir de suas respostas, que os mesmos fazem o uso de métodos diversificados (Gráfico 1).

Um dado interessante foi que $35 \%$ dos professores expuseram fazer o uso de práticas de campo e/ou no laboratório como métodos de ensino, uma vez que na maioria dos dados já apontados pelos discentes, o que prevalece no ensino, são as aulas expositivas tradicionais.

Gráfico 1 - Dados referentes aos métodos de ensino utilizados pelos docentes.

\footnotetext{
${ }^{8}$ Cumpre esclarecer que nessa pesquisa métodos alternativos estão se referindo a quaisquer métodos diferentes dos tradicionais, como por exemplo, aulas expositivas.
} 


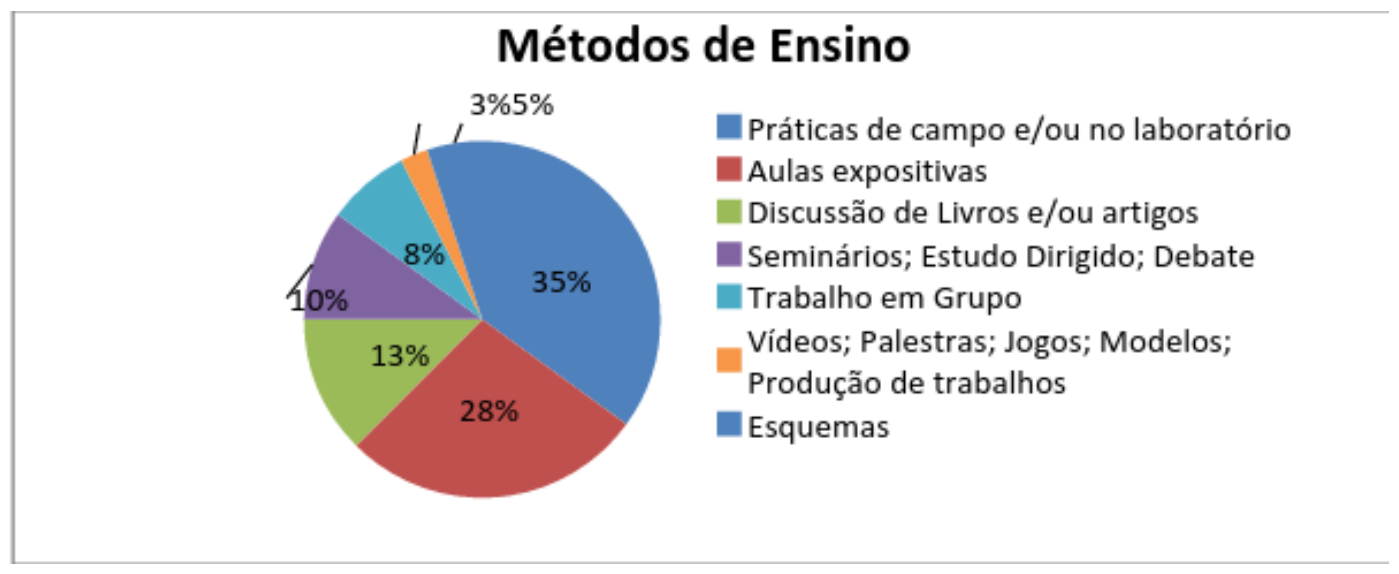

Fonte: Dados da própria autora. (2014)

Quando abordados sobre suas dificuldades em utilizar algum método de ensino em particular, constatamos a partir dos dados coletados, que 10 docentes afirmaram sentir dificuldades, e 5 não. Dentre as respostas destacamos o seguinte excerto:

"Sim. Método pouco comuns, considerados alternativos, pois não recebi conhecimento neste sentido, e não há estímulo por parte da universidade. Atividades que utilizem recursos audiovisuais, atividades de campo e extracurriculares". $\left(\mathrm{P}_{9} \mathrm{X}\right)$.

Pesquisadores do ensino de ciências e/ou Biologia (SASSERON, 2013, KRASILCHIK, 2009, MARANDINO, SELLES e FERREIRA, 2009, LORENZETTI; DELIZOICOV, 2001) apontam a importância do uso diversificado de métodos de ensino para favorecer a aprendizagem de modo mais significativo aos alunos, que vão desde a utilização de diferentes metodologias pelo professor, tais como investigação, interações discursivas e divulgação de ideias até ao uso de abordagem sistemática a partir do uso de diversas atividades articuladas no planejamento escolar, a saber: uso de artigos científicos, organização e participação em saídas de campos, participação em feiras de ciências, além do uso das novas tecnologias.

A dificuldade apontada por alguns professores de ambas as IFES na utilização de alguns métodos de ensino em particular, pode estar relacionado de acordo com Freitas e Villani (2002), ao docente enquanto aluno em sua graduação inicial ou mesmo continuada, no qual não recebeu o preparo adequado, ou até mesmo, se recebeu, preferiu resistir a essas mudanças, optando a trabalhar com o(s) método(s) o(s) qual (is) possui o domínio.

Quando indagados se consideravam importante o uso de métodos alternativos adequados às necessidades de sua disciplina, como também se estes propiciavam nos alunos um bom aprendizado, respectivamente obtivemos os seguintes resultados: 
Em relação a sua importância, dos 15 professores pesquisados, apenas 1 afirmou que não considera esse método importante para sua(s) disciplina (s), enquanto os demais docentes responderam que sim, e dentre estes, 1 professor questionou ter dificuldades para adequá-los a(s) suas disciplina (s), como mostra os excertos abaixo:

"Considero. No entanto tenho dificuldade para aplicar" $\left(\mathrm{P}_{7} \mathrm{X}\right)$.

"Não. Os métodos atualmente utilizados têm se mostrado adequado às disciplinas em questão" $\left(\mathrm{P}_{3} \mathrm{X}\right)$.

Já em relação se propiciavam nos alunos um bom aprendizado, verificou-se que os mesmos que consideravam importantes, afirmava nesse outro momento que esses métodos propiciavam esse bom aprendizado, e, no entanto, apenas 1 respondeu que dependeria da disciplina para que estes métodos pudessem propiciar esse aprendizado, como comprova os excertos a seguir:

"Sim. Pois a aula expositiva não consegue alcançar por si só o aprendizado por completo do aluno, que na maioria das vezes se destrai com conversas paralelas" $\left(\mathrm{P}_{3} \mathrm{Y}\right)$.

"Depende. Nem toda disciplina permite que os conteúdo seja trabalhado de modos alternativos seja por falta de base do aluno, seja pelo teor da informação". $\left(\mathrm{P}_{3} \mathrm{X}\right.$, grifo do autor)

De acordo com Macedo, Paula e Torres (1998, apud PACHANE; PEREIRA, 2004, p.5), “os próprios pós-graduandos criticam o despreparo pedagógico com que iniciam seu trabalho em sala de aula". Diante disso, Albuquerque et al (2004) elucida que os cursos de formação continuada, ou seja, a pós-graduação, "tornam-se significativas a medida que criam espaço para debates entre os pares, visando a formulação de propostas para se melhorar a prática pedagógica, considerando-a como um processo inconcluso" (p.4).

Perante a essas circunstâncias, Pachane e Pereira (2004, p.9) informam que

Torna-se necessário ao professor pensar numa nova forma de ensinar e aprender que inclua a ousadia de 'inovar as práticas de sala de aula, de trilhar caminhos inseguros, expondo-se e correndo riscos, não se apegando ao poder docente, com medo de dividi-lo com os alunos e também de desvencilhar-se da racionalidade única', pondo em ação outras habilidades que não apenas as cognitivas (grifo do autor).

Os docentes também foram interrogados sobre quais métodos consideravam que mais despertavam (Quadro 4) e menos despertavam (Quadro 5) interesses nos alunos. Os resultados foram organizados nos quadros a seguir:

Quadro 4 - Métodos que despertam mais interesse nos discentes na visão do docente.

\begin{tabular}{ccc}
\hline CATEGORIA & SUBCATEGORIAS & EXCERTOS \\
\hline & Campus $\mathrm{Y}$
\end{tabular}




\begin{tabular}{|c|c|c|}
\hline Seminário & Por está sendo avaliado & $\begin{array}{l}\text { "Seminários para que apresenta. Pois esta sendo } \\
\text { avaliado pelo professor e pelos alunos ali presente. } \\
\text { Para os que assistem existe desenteresse quando não } \\
\text { são cobrados e instigados à discutir" }\left(\mathbf{P}_{3}\right)\end{array}$ \\
\hline \multirow[b]{2}{*}{$\begin{array}{l}\text { Aulas de } \\
\text { campo }\end{array}$} & \multirow[b]{2}{*}{ Despertam curiosidade } & Campus X \\
\hline & & $\begin{array}{c}\text { "Estas despertam a curiosidade dos alunos sobre o } \\
\text { objeto de estudo e como este pode ser analisado." } \\
\qquad\left(\mathbf{( P}_{\mathbf{8}}\right) .\end{array}$ \\
\hline \multirow[b]{2}{*}{$\begin{array}{l}\text { Discussão de } \\
\text { artigos/ } \\
\text { debates }\end{array}$} & \multirow[b]{2}{*}{ Maior envolvimento } & Campus X \\
\hline & & "Porque eles se envolvem mais ativamente." $\left(\mathbf{P}_{\mathbf{3}}\right)$ \\
\hline \multirow{3}{*}{$\begin{array}{l}\text { Aulas no } \\
\text { laboratório }\end{array}$} & \multirow{3}{*}{ Forma descontraída } & Campus X \\
\hline & & $\begin{array}{l}\text { "pois há possibilidade deles vivenciarem alguma } \\
\text { parte da teoria na prática de uma forma bem mais } \\
\text { descontraída e diferente do cotidiano." }\left(\mathbf{P}_{\mathbf{2}}\right) \text {. }\end{array}$ \\
\hline & & $\begin{array}{l}\text { Desperta atenção por palpáveis e os próprios } \\
\text { manipulam, 'põe a mão na massa'. (Grifo do } \mathbf{P}_{6} \text { ) }\end{array}$ \\
\hline \multirow{5}{*}{ Vídeos } & \multirow{5}{*}{ Melhor aprendizagem } & $\begin{array}{r}\text { Campus X } \\
\end{array}$ \\
\hline & & $\begin{array}{l}\text { "Acredito que isso acontece devido ao uso de vários } \\
\text { sentidos, ajudando assim a fixar um novo } \\
\text { conteúdo." }\left(\mathbf{P}_{\mathbf{1 0}}\right) \text {. }\end{array}$ \\
\hline & & Campus $\mathbf{Y}$ \\
\hline & & $\begin{array}{l}\text { “[...] pois aproxima o educando do prazer diário a } \\
\text { necessidade da aquisição do conhecimento." }\left(\mathbf{P}_{1}\right) \text {. }\end{array}$ \\
\hline & & $\begin{array}{l}\text { "[...] porque o aprendizado ocorre de forma } \\
\text { agradável." }\left(\mathbf{P}_{2}\right) \text {. }\end{array}$ \\
\hline
\end{tabular}

Fonte: Dados da própria autora. (2014)

Com base nas respostas, observamos que os docentes possuem a mesma visão dos discentes em relação aos seminários como método de ensino.

A aula de campo e aulas no laboratório despertam no alunado a curiosidade de questionar, saber por que acontece e como acontece. Ambos os métodos de ensino proporcionam no aluno a ter contato direto com o ambiente e acaba se tornando imprescindível para aquisição de suas competências e habilidades.

Os vídeos didáticos são considerados, pelos docentes, como um dos recursos de fácil acesso que auxilia na complementação de uma aula expositiva. Corroborando com a afirmativa, Passau (2010), em sua pesquisa, constatou que 14 docentes dos 32 entrevistados, consideram os vídeos como "importante ferramenta audiovisual para trabalhar conteúdos na escola". (p.27). 
$\mathrm{Na}$ visão de alguns professores, discussão de artigos e/ou debates (Quadro 4) são considerados como um dos métodos que mais desperta interesse nos alunos, já que espera-se um melhor preparo dos discentes com o intuito de que possam participar efetivamente da discussão, superando dificuldades de articulação e problemas com timidez do alunado, além de ser um método, que quando bem explorado em sala de aula pode estimular o senso crítico dos discentes.

Quadro 5 - Métodos que despertam menos interesse nos discentes na visão do docente.

\begin{tabular}{|c|c|c|}
\hline CATEGORIA & SUBCATEGORIAS & EXCERTOS \\
\hline \multirow[b]{2}{*}{ Seminários } & \multirow[b]{2}{*}{$\begin{array}{l}\text { Dificuldade na } \\
\text { transmissão do } \\
\text { conhecimento }\end{array}$} & Campus $\mathbf{X}$ \\
\hline & & $\begin{array}{l}\text { "Por que na prática apenas o grupo responsável pelo } \\
\text { "tema" estuda o assunto e nem sempre o transmitem } \\
\text { de modo satisfatório para o resto da turma." }\left(\mathbf{P}_{\mathbf{3}}\right)\end{array}$ \\
\hline \multirow[b]{2}{*}{$\begin{array}{l}\text { Trabalhos } \\
\text { escritos (estudo } \\
\text { dirigido/ } \\
\text { resenhas) }\end{array}$} & \multirow[b]{2}{*}{ Estimula o senso crítico } & Campus $\mathbf{Y}$ \\
\hline & & $\begin{array}{c}\text { “[...] seja pela monotonia ou não habilidade de } \\
\text { escrever expondo seu senso crítico ou até mesmo } \\
\text { simplesmente pelo fato de transcrever algo de forma } \\
\text { mecânica". }\left(\mathbf{P}_{\mathbf{2}}\right)\end{array}$ \\
\hline \multirow{5}{*}{$\begin{array}{c}\text { Aulas } \\
\text { expositivas }\end{array}$} & \multirow{3}{*}{ Cansativa/ enfadonha } & Campus X \\
\hline & & $\begin{array}{l}\text { "Tende a ser enfadonha, mesmo o professor tendo } \\
\text { excelente didática. Muito demorada. O aluno não } \\
\text { interage da mesma maneira que na prática." }\left(\mathbf{P}_{\mathbf{6}}\right)\end{array}$ \\
\hline & & $\begin{array}{l}\text { "Estas são cansativas pois os alunos em sua maioria } \\
\text { não tem o hábito de ler, nem mesmo os slides } \\
\text { repassados pelo professor." }\left(\mathbf{P}_{\mathbf{8}}\right) \text {. }\end{array}$ \\
\hline & \multirow[t]{2}{*}{ Sem cobranças } & Campus Y \\
\hline & & “[...] não há cobrança ao término da aula.” $\left(\mathbf{P}_{\mathbf{6}}\right)$ \\
\hline
\end{tabular}

Fonte: Dados da própria autora. (2014)

Como observado no quadro acima, tanto o trabalho escrito, como estudo dirigido e resenhas, é considerado por alguns docentes como métodos que não despertam interesse nos discentes. Isso acontece por que parte deles não estão habituados a trabalharem seu senso crítico, ou seja, não tem a capacidade de criar sua própria opinião. E de certa forma, para fazer resenhas necessita que você exponha seu ponto de vista.

Da mesma forma que já foi discutido anteriormente na visão dos alunos em relação às aulas expositivas, os docentes também as consideram enfadonhas e cansativas. Dando suporte ao excerto de $\mathrm{P}_{8} \mathrm{X}$, “Estas são cansativas pois os alunos em sua maioria não tem o hábito de ler, nem mesmo 
os slides repassados pelo professor”. Marasini (2010, p.17) em observações durante sua pesquisa constatou que

[...] os alunos acabam tendo a tendência natural de não prestar atenção ao que está sendo apresentado, seja pela comodidade de ter acesso aos arquivos do professor depois das aulas, seja pelo fato de que o método pode tornar a aula monótona e visualmente cansativa.

Essa afirmação nos leva a refletir sobre a necessidade do professor em rever os métodos utilizados em sala de aula a fim de tomar conhecimento se a forma escolhida por ele para abordar os conteúdos está sendo eficaz e está promovendo um aprendizado efetivo dos alunos.

\section{Áreas da Biologia versus uso de aulas diferenciadas}

A Biologia possui diversas áreas apresentando complexidades distintas que cabe ao docente trabalhá-las de maneira que o aluno alcance um conhecimento significativo, possibilitando consequentemente articular a teoria aprendida com a prática.

Quando se abordou a questão referente à área ${ }^{9}$ da Biologia que os discentes e docentes consideram ser mais importantes o uso de aulas diferenciadas, foi possível observar que as respostas (Gráfico 2) de ambos os sujeitos de pesquisa variavam de acordo com seus pontos de vista.

Gráfico 2- Dados referentes às áreas mais importantes para uso de aulas diferenciadas.

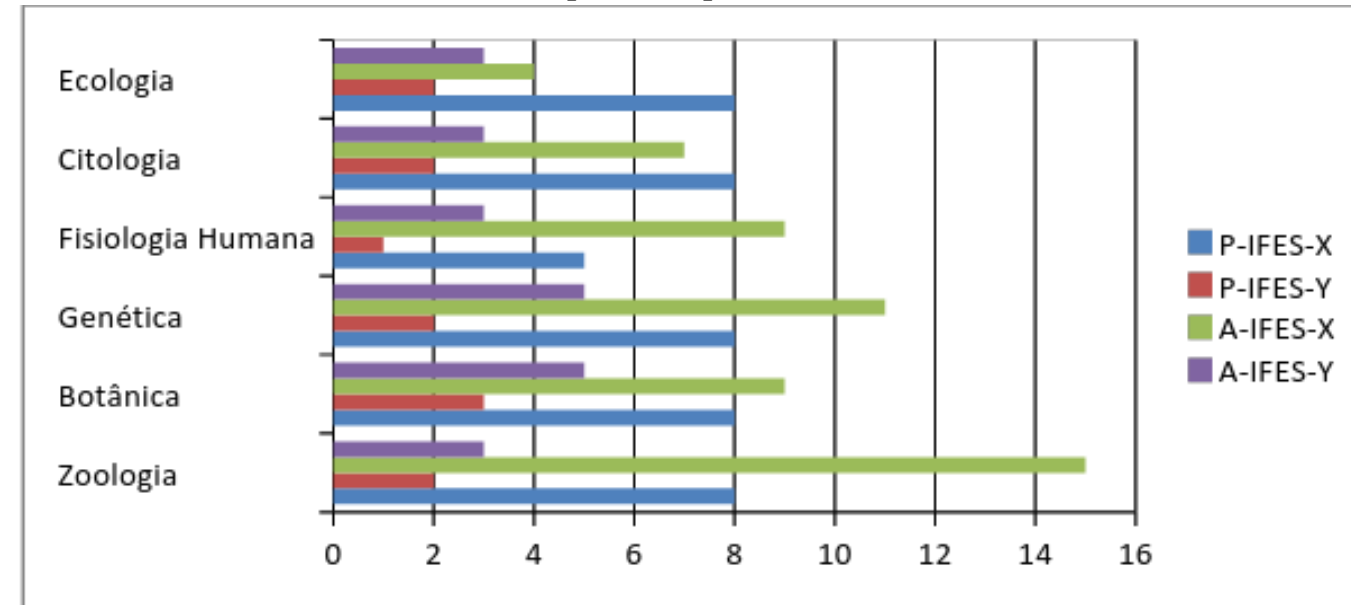

Fonte: Dados da própria autora. (2014)

Disciplina como Zoologia, possivelmente, é uma das disciplinas que mais tem aulas práticas na graduação, assim como a Botânica. A Genética é considerada por muitos como uma disciplina de difícil compreensão, e aulas diferenciadas com o uso de diversos métodos e recursos didáticos podem facilitar a aprendizagem.

\footnotetext{
${ }^{9}$ O número de citações ultrapassa o total de discentes e docentes investigados, uma vez que mais de uma área pode ter sido citada pelo mesmo.
} 
Dentre as variadas opções escolhidas pelos participantes, 12 do total dos sujeitos pesquisados responderam que todas as áreas citadas no gráfico acima seriam importantes o uso de aulas diferenciadas. Diante das respostas obtidas, selecionamos um excerto o qual resume a importância do uso de aulas diferenciadas em todas as áreas.

\footnotetext{
"Na minha opinião, não é possível ensinar Biologia somente utilizando-se de aulas tradicionais. Biologia é uma área eminentemente prática, assim, restringir o ensino à aulas expositivas certamente não propiciará aos alunos uma boa formação". $\left(\mathrm{P}_{1} \mathrm{X}\right)$
}

Diante disso, Rosa (2012, p.8), elucida que "é função do professor, proporcionar ao aluno uma aula diferenciada, motivar o aluno, propiciar a aquisição de novos conhecimentos e saberes, que vão além do que pode ser aprendido na sala de aula.”.

\section{CONSIDERAÇÕES FINAIS}

Nessa pesquisa buscamos conhecer os diferentes métodos de ensino utilizados por docentes nos cursos de Licenciatura em Ciências Biológicas em duas IFES, bem como estes métodos são aceitos (ou não) pelos discentes desses cursos e se auxiliam no processo de ensino aprendizagem dos mesmos.

De acordo com Pozo (2000), Krasilchik (2009), Marasini (2010), Berlesi (2011) e Rosa (2012), o uso de métodos alternativos vem crescendo cada vez mais independentemente de qualquer que seja a disciplina, uma vez que estes propiciam nos discentes uma aquisição de conhecimentos significativos dos conteúdos trabalhados em sala de aula.

Notamos com base nos resultados, que dentre os vários métodos mencionados, observamos que as aulas expositivas na visão dos discentes, embora sejam consideradas como métodos que causam desinteresse pela disciplina, estas também foram vistas como uma das práticas mais importantes para aquisição de conhecimentos, uma vez que permite o professor transmitir seus conhecimentos, apontando questões consideradas relevantes para serem abordadas.

No entanto, é importante destacar que uma parte considerável dos docentes do ES está buscando fornecer uma aprendizagem sólida aos discentes e estão permitindo inovar as práticas pedagógicas, diversificando seus métodos de ensino, interferindo constantemente na motivação dos alunos, estimulando o senso crítico para que, dessa forma, adquiram habilidades extremamente essenciais para o seu futuro papel de educador.

Importante ressaltar que os licenciandos em Ciências Biológicas, possivelmente, atuarão como professores e com certeza os docentes que tiveram na universidade irão, de certa forma, influenciar na sua prática pedagógica. Concordamos com Albuquerque et al (2004) quando afirmam 
que as referências deixadas pelos modelos de docência, tanto da educação básica (ensino fundamental e médio) como também da educação superior, certamente influenciarão na formulação de um exemplo do ser docente em algum momento do exercício profissional.

A partir dos resultados obtidos, reforçamos a importância de pesquisas voltadas para a análise e reflexão sobre a Didática em curso de licenciaturas, sejam elas sobre práticas pedagógicas, currículos, métodos de ensino, recursos didáticos entre outras, a fim que sejam formados futuros profissionais competentes e seguros em exercer com segurança uma profissão tão importante como a de educadores.

\section{REFERÊNCIAS}

ALBUQUERQUE, A. M. et al. Docentes Universitários: Quem São, O Que Sabem E O Que Fazem. $4^{\mathbf{0}}$ Encuentro Nacional y Latinoamericano: La Universidad como objeto de estudio Eje 8.,2004. Disponível em $<$ http://rapes.unsl.edu.ar/Congresos_realizados/Congresos/IV\%20Encuentro\%20-\%20Oct2004/eje8/032.htm >. Acesso em: 23 fev. 2014.

AUSUBEL, D. P.; NOVAK, J. D.; HANESIAN, H. Psicologia educacional. 2. ed. Rio de Janeiro: Interamericana, 1980. p.96-133 apud OLIVEIRA, S. S. Concepções alternativas e ensino de biologia: como utilizar estratégias diferenciadas na formação inicial de Licenciados. Revista Educar, Curitiba, n. 26, p. 233-250, 2005. Editora UFPR.

BARDIN, L. Análise de conteúdo. Lisboa, Portugal: Edições 70, 2009.

BARREIRO, I. M. F. Prática de ensino e estágio supervisionado na formação de professores. São Paulo: Avercamp, 2006.

BERLESI, M. S. Aulas diferentes fazem diferença no aprendizado dos (as) alunos (as). 2011.38f. Trabalho de Conclusão de Curso (Licenciatura). Universidade Federal do Rio Grande do Sul, Porto Alegre, 2011.

BOGDAN, R.; BIKLEN, S. Investigação qualitativa em educação: uma introdução à teoria e aos métodos. Porto: Porto, 1994.336p.

BRITO, M. R. F. ENADE 2005: Perfil, desempenho e razão da opção dos estudantes pelas Licenciaturas. Avaliação, Campinas; Sorocaba, SP, v. 12, n. 3, p. 401- 443, set. 2007.

CARLINI, A.L. Procedimentos de ensino: Escolher e Decidir. In: SCARPATO, M. Os procedimentos de ensino fazem a aula acontecer. São Paulo: Avercamp, 2004.

FARIAS, I. M. S.; SALES, J. O. C. B.; BRAGA, M. M. S.C.; FRANÇA, M.S. L. M. Didática e Docência: aprendendo a profissão. Fortaleza: Líber Livros, 2008, 180p. 
FREITAS, D.; VILLANI, A. Formação de professores de Ciências: um desafio sem limites. Investigações em Ensino de Ciências - V7(3), pp. 215-230, 2002. Disponível em: <http://www.if.ufrgs.br/ienci/artigos/Artigo_ID90/v7_n3_a2002.pdf > Acesso em: 23 fev. 2014.

GATTI, B. A. A construção da pesquisa em educação no Brasil. Brasília, DF: Plano Editora, 2002.

GIL, A. C. Métodos e técnicas de pesquisa social. 5. ed. São Paulo: Atlas, 1999.

INSTITUTO NACIONAL DE ESTUDOS E PESQUISAS EDUCACIONAIS. Censo da educação superior 2013: resumo técnico. - Brasília : Instituto Nacional de Estudos e Pesquisas Educacionais Anísio Teixeira, 2015. Disponível em

<http://download.inep.gov.br/download/superior/censo/2013/resumo_tecnico_censo_educacao_sup erior_2013.pdf>. Data de acesso: 17 jul. 2017.

KRASILCHIK, M. Biologia- ensino prático. In: CALDEIRA, A. M. A.; ARAUJO, E. S. N. N. (org.). Introdução à Didática da Biologia. São Paulo. Escrituras editora, 2009, p. 249-258.

KRASILCHIK, M. Prática de ensino de Biologia. São Paulo. Editora: Harper \& Row do Brasil.1983. 203p.

LIBÂNEO, J. C. Didática. São Paulo: Cortez, 1994.

LIMA, K. E. C.; VASCONCELOS, S.D. Análise da Metodologia de Ensino de Ciências das Escolas da Rede Municipal de Recife. In: Ensaio: Avaliação e Políticas Públicas em Educação. Rio de Janeiro, v.14, n.52, p. 397- 412, jul./set. 2006. Disponível em < http://www.scielo.br/ensaio>. Acesso em: 27 nov. 2013.

LORENZETTI, L.; DELIZOICOV, D. Alfabetização Científica no contexto das séries inicias. Ensaio - Pesquisa em Educação em Ciências, v. 3, n. 1, p. 1-17, 2001.

MACEDO, D. V. E.; PAULA, B. B.; TORRES. Formação pedagógica dos estudantes de pósgraduação.Campinas: Unicamp: São Paulo: USP, 1998 In: PACHANE, G. G.; PEREIRA, E. M. A. A importância da formação didático-pedagógica e a construção de um novo perfil para docentes universitários. Revista Iberoamericana de Educación, Espanha. n. 33/34, p. 1-13, 2004.

MARANDINO, M.; SELLES, S. E.; FERREIRA, M. S. Ensino de Biologia: histórias e práticas em diferentes espaços educativos. 1. ed. São Paulo: Cortez, 2009.

MARASINI, A. B. A utilização de recursos didático-pedagógicos no ensino de Biologia.2010. 28f. Trabalho de conclusão de curso (Licenciatura). Universidade Federal do Rio Grande do Sul, Porto Alegre, 2010.

ODA, W. ; DELIZOICOV, D. Docência no Ensino Superior: as disciplinas Parasitologia e Microbiologia na formação de professores de Biologia. Revista Brasileira de Pesquisa em Educação em Ciências. v. 11, n. 3, p. 101-121, 2011. 
PACHANE, G. G.; PEREIRA, E. M. A. A importância da formação didático-pedagógica e a construção de um novo perfil para docentes universitários. Revista Iberoamericana de Educación, Espanha. n. 33/34, p. 1-13, 2004.

PASSAU, A. S. Análise dos fatores que influenciam na utilização de filmes como recurso didático pelos docentes de Ciências. 2010. 46f. Trabalho de conclusão de curso (Especialização). Universidade do Estado do Rio de Janeiro, Rio de Janeiro, 2010.

PIRES, K. C. P. Perfil do professor do curso de graduação de Biologia na Universidade Estadual de Goiás - Unidade Laranjeiras. 2007. 63f. Trabalho de conclusão de curso (Especialização) - Universidade Estadual de Goiás, Goiânia, 2007.

POZO, J. I. Teorias Cognitivas da Aprendizagem. 3. ed. Porto Alegre: Artes Médicas, 2000.

QUADROS, A. L.; A formação de professores: um olhar para a Química. In: TEIXEIRA, P. M. M. (org.). Ensino de Ciências: Pesquisas e Reflexões. Ribeirão Preto: Holos. 2006, p. 109-113.

ROSA, A. B. Aula diferenciada e seus efeitos na aprendizagem dos alunos: o que os professores de Biologia têm a dizer sobre isso?. 2012. 43f. . Trabalho de conclusão de curso (Licenciatura). Universidade Federal do Rio Grande do Sul, Porto Alegre, 2012.

SASSERON, L. H. Interações discursivas e investigação em sala de aula: o papel do professor. In: CARVALHO, A. M. P. de. (org). Ensino de ciências por investigação. São Paulo: Cengage Learning, 2013.

SILVA, E. R. Uma experiência de ensino de biologia numa perspectiva inovadora. 2010.172f. Dissertação (Mestrado) - Universidade da Madeira, Funchal, 2010.

SONCINI, M. I. I. ; CASTILHO JÚNIOR, M. Biologia. Convênio MEC/PUC. São Paulo, 1988.

VEIGA, I. P. A.; A prática pedagógica do professor de didática. 11. ed. Campinas: Papirus, 1989. 